\title{
Carcinogenesis in the GI Tract: From Morphology to Genetics and Back Again
}

\author{
Mark Redston, M.D., F.R.C.P.C. \\ Department of Pathology and Laboratory Medicine, Mount Sinai Hospital, and Department of Laboratory \\ Medicine and Pathobiology, University of Toronto, Toronto, Ontario, Canada
}

The genetic alterations in colorectal cancer progression are determined by one of two separate and distinct underlying pathways of genomic instability. The first pathway, chromosomal instability, is characterized by allelic losses and aneuploidy. The second pathway, microsatellite instability, is characterized by an abundance of subtle DNA mutations and diploidy. Although the genes causing chromosomal instability remain unknown, microsatellite instability is caused by inactivation of a DNA mismatch repair gene (predominantly MLH1 or MSH2). Microsatellite instability is present in $15 \%$ of colorectal cancers, and is diagnosed by analysis of tumor DNA from paraffin blocks and by demonstration of loss of mismatch repair protein expression in cancers. In addition to the unique profile of genetic alterations, colorectal cancers with microsatellite instability have distinct pathologic features and improved survival. Finally, cancers from most patients with hereditary non-polyposis colorectal cancer (or Lynch syndrome) have microsatellite instability due to germline mutations in the DNA mismatch repair genes. Identification of the microsatellite instability pathway has enormous implications for the clinical investigation and management of colorectal cancer patients.

KEY WORDS: Colorectal cancer, Chromosomal instability, Microsatellite instability, DNA mismatch repair, Hereditary non-polyposis colorectal cancer.

Mod Pathol 2001;14(3):236-245

\section{Genetic Model of Colorectal Cancer}

The past 15 years have been witness to the remarkable evolution of the genetic model of human

Copyright () 2001 by The United States and Canadian Academy of Pathology, Inc.

VOL. 14, NO. 3, P. 236, 2001 Printed in the U.S.A.

Date of acceptance: December 12, 2000.

Address reprint requests to: Mark Redston, M.D., Department of Pathology and Laboratory Medicine, Mount Sinai Hospital, Suite 600, 600 University Avenue, Toronto, Ontario, Canada M5G-1X5; e-mail: mredston@ mtsinai.on.ca; fax: 416-586-8628. cancer development and progression. It is now generally accepted that cancer is in large part a genetic disease. This includes both inherited genetic factors that influence predisposition to cancer, and the genetic targets of neoplastic progression that confer altered growth capacity to neoplastic cells.

It is no coincidence that colorectal cancer has evolved as the paradigm on which many of our current theories of cancer genetics are based. This has occurred for a number of different reasons. First, colorectal cancer is the second most frequent malignancy in North America. Second, most colorectal cancers are preceded by a clearly identifiable precursor lesion, the adenoma. Third, colorectal neoplasms are readily available for research investigations because surgical therapy is the mainstay of treatment and mucosal-based tumors are simply dissected for analysis. And fourth, inherited colorectal cancer is comprised of a number of distinct genetic syndromes, many of which have recently been well-characterized.

Most pathologists are familiar with the genetic model of colorectal cancer progression as proposed by Vogelstein's group as well as a number of other investigators $(1,2)$. These studies have carefully delineated that there are a number of different alterations in genes controlling cell growth, and that these accumulate across a spectrum of neoplasms with increasingly abnormal morphology and phenotypic features (such as mutations in $A P C, K R A S$, and $p 53$, as well as subchromosomal deletions or sites of loss of heterozygosity) (reviewed in Ref. 3).

Recently, a number of morphologic observations have led to some new molecular genetic insights into colorectal neoplasia. In turn, these new findings have important implications to the practicing surgical pathologist. This review will describe these recent advances and highlight their importance, both in terms of understanding the biology of this disease, as well as the possible use of these findings in diagnosis and classification of sporadic and hereditary colorectal cancer syndromes. 


\section{Gatekeepers and Caretakers in Colorectal Neoplasia}

Conceptually, a gatekeeper in human neoplasia refers to a gene that controls the initiation (or is rate-limiting) of a neoplasm in a specific tissue (4). That is to say, the development of an early neoplasm in this tissue is almost universally associated with (and possibly requires) alteration of this target gene. Mutation and subsequent inactivation of the adenomatous polyposis coli (APC) tumor suppressor gene in colorectal neoplasia perhaps best exemplifies the gatekeeper model (5). In contrast, a caretaker refers to a gene that controls the rate of accumulation of genetic alterations (or mutations) during neoplastic progression. The DNA mismatch repair genes serve as the prototypic model of caretaker genes in human neoplasia, and are discussed below.

$A P C$ was originally identified as the tumor suppressor gene that causes familial adenomatous polyposis coli (FAP) $(6,7)$. Although APC has a number of putative functions, most ascribe the role in neoplasia to controlling the WNT signaling pathway via regulation of beta-catenin levels ( $A P C$ reviewed in Ref. 8, beta-catenin reviewed in Ref. 9). APC inactivation in tumors leads to beta-catenin stabilization, activation of the TCF transcription factor, and subsequent up-regulation of c-MYC, Cyclin-D1, and other genes $(10,11)$. Individuals affected by FAP usually have germ line $A P C$ mutations that predict protein truncation and loss of function (5-7). These mutations are directly associated with the development of thousands of colonic adenomas at a very young age. Small intestinal adenomas, gastric adenomas, desmoid tumors, and thyroid neoplasms also may occur; however, there is a relative absence of neoplasia at most other organ sites. Following the model of several other human tumor suppressor genes, $A P C$ mutations were subsequently identified in most colorectal cancers, confirming the critical role of this alteration in colorectal neoplasia in general $(3,5)$.

The critical evidence supporting the possible gatekeeper role of APC in colorectal neoplasia came from studies of the timing of inactivation during neoplastic development. Even when very small tubular adenomas are examined, there is evidence for inactivation of both $A P C$ alleles, supporting the early occurrence of these alterations. This was subsequently confirmed by studies of the earliest dissectable neoplasms, aberrant crypt foci (ACF) (Fig. 1). ACF are collections of 3 to 20 or more adjacent crypts that share morphologic abnormalities when examined in methylene blue stained mucosal sheets by dissecting microscope (reviewed in Refs. 12 and 13). This preparation allows visualization into the crypt lumen (which has no staining) and is contrasted by staining of the crypt epithelial nuclei (giving the appearance of tightly packed together blue donuts with central white holes). Typically,
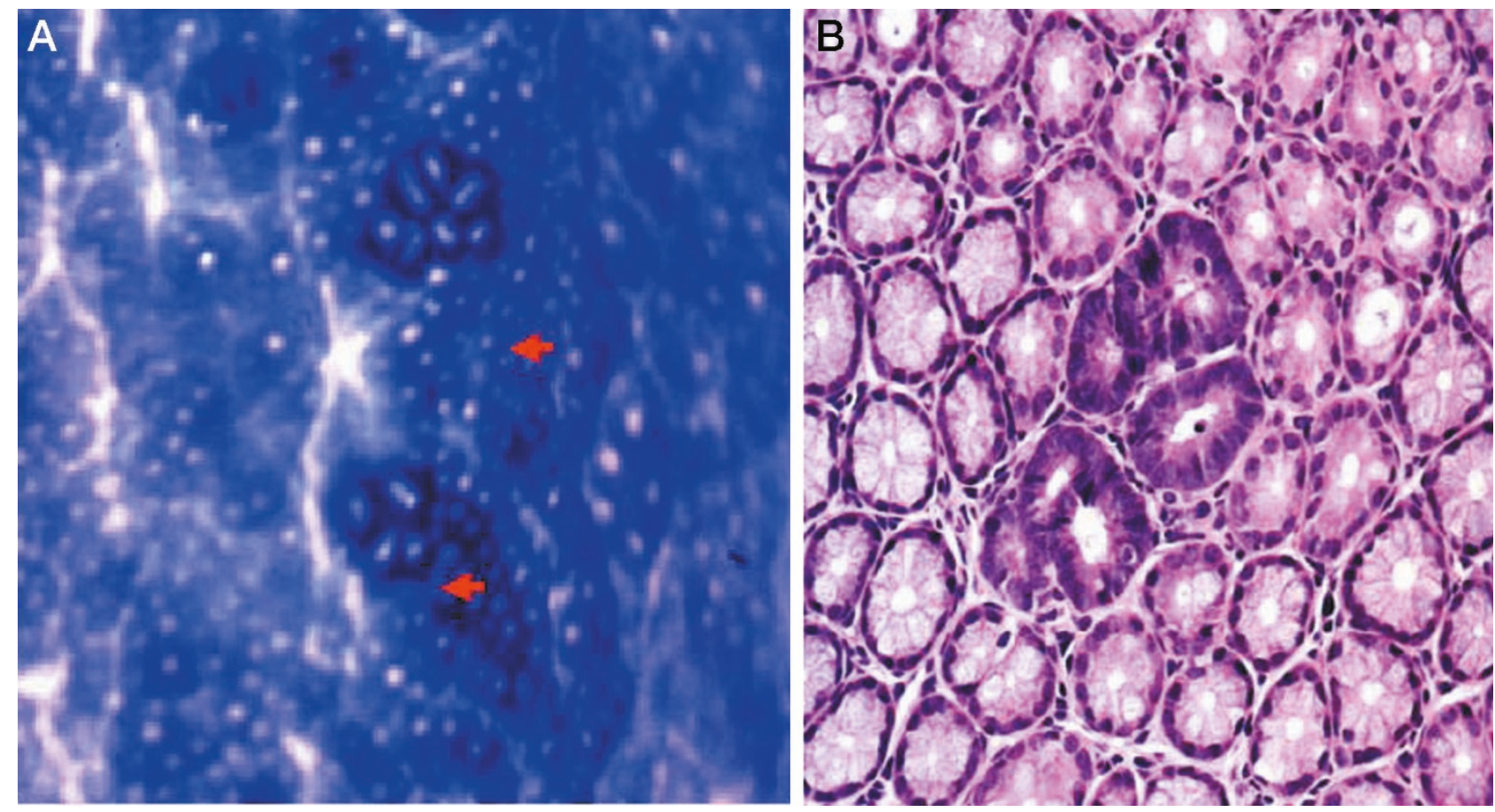

FIGURE 1. Aberrant Crypt Foci. Left, methylene blue stained colonic mucosal sheet viewed under dissecting microscope. Crypt lumens are viewed on end, and appear as white spots. Aberrant crypt foci (arrows) have dilated diameters, increased staining, and slit-like lumens. Right, histologic examination of these aberrant crypt foci reveals dysplasia. These tiny microscopic adenomas are associated with bi-allelic inactivation of the $A P C$ gene. 
ACF have dilated crypt diameters, and increased nuclear staining, with either serrated or slit-like (rather than rounded) lumens. Most histopathologic studies have confirmed two types of ACF, either hyperplastic (akin to tiny hyperplastic polyps) or dysplastic (akin to tiny adenomas). Dysplastic ACF are analogous to the microadenomas or unicryptal adenomas that all pathologists are familiar with in the grossly normal colons of patients with familial adenomatous polyposis. Remarkably, dysplastic ACF are almost universally accompanied by $A P C$ mutations whereas similar mutations have never been conclusively identified in hyperplastic ACF, suggesting that $A P C$ mutations are the molecular determinant of dysplasia (14).

The final evidence comes from the observation that mice with heterozygous inactivation of the mouse homologue of APC develop multiple intestinal neoplasms (accounting for the gene name $\mathrm{Min}$ ) (15). Analogous to humans with FAP, both copies of the Min gene are mutated in even the very tiniest neoplasms from these mice (16).

In recent years, there have been colorectal neoplasms identified that do not harbor $A P C$ mutations. Interestingly, these tumors often have mutations in the beta-catenin gene, a WNT signaling pathway component located downstream of APC, suggesting that the importance lies in up-regulation of this signaling pathway, not necessarily in alteration of $A P C$ itself $(9,17)$.

Although it is not yet clear whether all human tissues will have a gatekeeper gene, this function has been ascribed to the $V H L$ gene for renal cell carcinoma and to the $P T C H$ gene for basal cell carcinomas. Critical translocations may have similar roles in some hematologic neoplasms and soft tissue tumors.

\section{Attenuated Forms of Familial Adenomatous Polyposis}

In individuals with familial adenomatous polyposis, APC mutations are usually identified in the middle third of the gene (8). Although 100 adenomas are required by definition, most of these patients have thousands of adenomas. Separate from classic familial adenomatous polyposis, a different subset of patients and families exist that have inherited predisposition toward the development of 20 to 100 adenomas. Termed attenuated familial adenomatous polyposis, these individuals usually have $A P C$ mutations at the extreme $5^{\prime}$ or 3 ' ends of the gene $(18,19)$. Although the exact mechanisms are not understood, these mutations presumably exert less functional significance. Importantly, attenuated familial adenomatous polyposis is a less well recognized clinical entity, and is often first identified by the pathologist at the time of exami- nation of a resection specimen for a cancer or large adenoma. Correct identification requires histologic examination of all available synchronous polyps to differentiate adenomas and hyperplastic polyps. At our institution, these are examined by submitting multiple polyp "decapitations" (which are easily removed with scissors) in a single cassette. Future genetic work-up and risk stratification is dependent on explicitly delineating the numbers of adenomas and hyperplastic polyps. Finally, the existence of attenuated familial adenomatous polyposis raises the possibility that other weakly penetrant alleles could contribute to the occurrence of less distinct multiple adenoma syndromes.

\section{APC 11307K Allele in the Ashkenazim}

Originally identified in a young patient with multiple adenomas, the $A P C \mathrm{I} 1307 \mathrm{~K}$ allele is a recurrent substitution polymorphism present in about $7 \%$ of individuals of Ashkenazic Jewish ancestry (20). Although the isoleucine to lysine substitution is not thought to be of functional significance, the nucleotide alteration results in the creation of a novel mononucleotide tract (...GAAATAAAAG...to...GAAAAAAAAG...). Mononucleotide tracts are known to be unstable during DNA replication (due to strand slippage), and thus the I1307K is effectively hypermutable compared with the wild type sequence. This renders the APC gatekeeper more susceptible to mutation and inactivation, and carriers of this allele are about 1.7 times more likely to develop colorectal cancer $(20,21)$. Consistent with this gatekeeper susceptibility, carriers of the I1307K allele are significantly more likely to develop multiple adenomas, usually between 3 to 20 adenomas in total (22). This finding also supports the notion that all patients with multiple adenomas may have significant genetic determinants, again emphasizing the role of the pathologist in carefully documenting all polyps and interacting directly with hereditary cancer clinics.

\section{Mutator Phenotype and Genomic Instability}

Many investigations have demonstrated that the spontaneous basal mutation rate in normal human cells is not high enough to account for the number of mutations that accumulate in cancer cells. This led to the hypothesis that neoplastic cells must acquire a mutator phenotype, wherein mutations are acquired (and tolerated) faster than the basal rates in normal cells $(23,24)$. Failure of any of the cellular caretakers involved in maintaining replication fidelity will result in a mutator phenotype (also known as genome instability) (4). This includes alterations in DNA replication machinery (not known to be common in cancer), alterations in DNA dam- 
age sensors and regulators (such as cell cycle check point genes; of increasing importance in cancersee Ref. 25) and inactivation of DNA mismatch repair (the best characterized form of genome instability—see below).

\section{Hereditary Non-Polyposis Colorectal Cancer} (HNPCC) and Familial Colorectal Cancer

The role of DNA mismatch repair in human cancer was primarily identified from the study of families with HNPCC. HNPCC is a highly penetrant hereditary cancer syndrome originally described by a pathologist (reviewed in Refs. 26 and 27). Some HNPCC families have only colorectal cancers (previously known as Lynch I), whereas others have a number of extracolonic cancers (including endometrial, gastric, ureter, brain, and bile duct; previously known as Lynch II). In addition, Muir-Torre syndrome (visceral, predominantly colorectal malignancies, and skin tumors, particularly sebaceous neoplasms and keratoacanthomas) is also recognized as a component of HNPCC. Interestingly, the same genetic defects seem to underlie all three variants of HNPCC.

To assist in the recognition and management of HNPCC patients, a number of family history criteria have been proposed. The Amsterdam criteria are the most widely used, although a number of other less stringent criteria have also been developed (26-28). Similarly, estimates of the proportion of colorectal cancer due to HNPCC have also varied widely, in part due to non-uniform application of criteria and biases inherent in hospital-based series. Most recent population-based studies indicate that about 2 to $3 \%$ of all colorectal cancer is due to HNPCC $(26,27)$. In past, because HNPCC cancers were identifiable by family history, pathologists have not played a significant role in diagnosis and management.

Finally, about $10^{-20} \%$ of colorectal cancer exhibits lesser degrees of familial clustering, and is broadly categorized as intermediate risk. Although a component of these may contain the same genetic defects as HNPCC, the genetic basis of most remains largely unknown at the present time.

\section{DNA Mismatch Repair Deficiency in Colorectal Cancer}

The tumors from about three quarters of HNPCC families display a DNA alteration termed high frequency microsatellite instability (MSI-H). This was independently identified by three different laboratories, and originally referred to as ubiquitous somatic mutation, replication error, and microsatellite instability (29-31). Recognized to be the result of DNA mismatch repair deficiency, MSI-H is de- fined by the presence of altered sizes of repetitive DNA sequences due to dramatic increases in spontaneous mutation rates. DNA mismatch repair is a multi-protein complex involved in correcting 1 to 3 base mismatches that occur during replication (reviewed in Refs. 32 and 33). Germ line mutations in one of several DNA mismatch genes (including MLH1, MSH2, PMS2, and MSH6) are usually found in HNPCC patients whose tumors have MSI-H. These mutations usually predict truncated protein products, and result in inactivation of DNA mismatch repair (reviewed in Ref. 34).

Interestingly, MSI-H is also present in about $10^{-20} \%$ of sporadic colorectal cancers, as well as an approximately similar proportion of endometrial and gastric cancers. In the sporadic cancers, DNA mismatch repair deficiency is usually the result of MLH1 inactivation due to methylation suppression of the $M L H 1$ promoter region (35-37).

\section{Microsatellite Instability Testing}

As in many other emerging fields, early investigations of microsatellite instability were difficult to interpret and compare due to differences in definitions and criteria for testing and classifying. Two NIH-sponsored conferences led to the development of standardized criteria for genetic loci for testing and interpreting the results of microsatellite instability (38). Essentially, tumor DNA is compared with normal DNA at five loci (microsatellites). If no alterations are identified, the tumor is considered to be microsatellite stable (MSS). If size alterations or shifts are identified at two or more loci, the tumor is classified as MSI-H. If only one locus is altered, five additional loci are tested. If only one to three loci (of 10 total tested) have shifts, the tumor is considered to have low frequency MSI (MSI-L). If four or more loci have shifts, the tumor is MSI-H. DNA mismatch repair inactivation is almost universally associated with tumors that are MSI-H. Although some MSI-L tumors have inactivation of MSH6, the exact genetic basis of most of these tumors is not clearly defined.

There are a number of different methods available to perform MSI testing. Gel electrophoresis of radioactively labeled PCR products is the most widely used approach. Many larger genetics labs with higher throughput are utilizing fluorescent labeled PCR reactions and analysis of fragment sizes by automated sequencers. Finally, the mononuclotide loci (BAT25, BAT26, and BAT40) have more than $90 \%$ sensitivity by themselves, and are readily analyzed on high resolution agarose gels with routine staining methods as well as by SSCP. 


\section{DNA Mismatch Repair Immunohistochemistry}

Most DNA mismatch repair gene mutations associated with MSI-H cancers predict protein truncations. These are usually associated with absent protein expression in the tumor, due to either message or protein instability and degradation. As a result, immunohistochemical identification of absent MLH1 or MSH2 protein expression is a valuable adjunct to characterizing mismatch repair deficiency (Fig. 2). In our experience, absence of protein expression has a $100 \%$ correlation with truncating mutations in either of these genes (39). The immunohistochemical findings in tumors associated with substitution mutations in mismatch repair genes are not as well characterized. Furthermore, about 20 to $30 \%$ of MSI-H tumors have intact MLH1 and MSH2, and are presumably due to subtle alterations, or mutations in other mismatch repair or related genes. Immunohistochemistry for MSH6 has also been reported, but MSH6 mutation and inactivation is a common downstream target in about $40 \%$ of MSI-H tumors, and is therefore of less utility for characterizing underlying defects (40).
Germ Line Testing for DNA Mismatch Repair Gene Mutations

Following identification of MSI-H and mismatch repair gene deficiency in the tumors of appropriate high-risk families, there are a number of different approaches that can be taken to further characterize the underlying mutation (19). Identification of truncated protein products utilizing the in vitro synthesized protein assay or protein truncation test are commonly used initial screening methods. Many labs follow this with SSCP or direct sequencing if no truncations are identified, although some labs begin with sequencing-based approaches initially. Most genetic labs currently test for mutations in $M L H 1$ and $M S H 2$, and screening for mutations in other genes is usually only performed in a research setting. Finally, Southern blot analysis to detect deletions and rearrangements is performed at some labs for high-risk families with MSI-H cancers in which no mutations can be identified. Overall, mutations are split primarily between $M L H 1$ and MSH2, and are less frequently identified in MSH6 and PMS2 (19, 26-28, 34, 41).
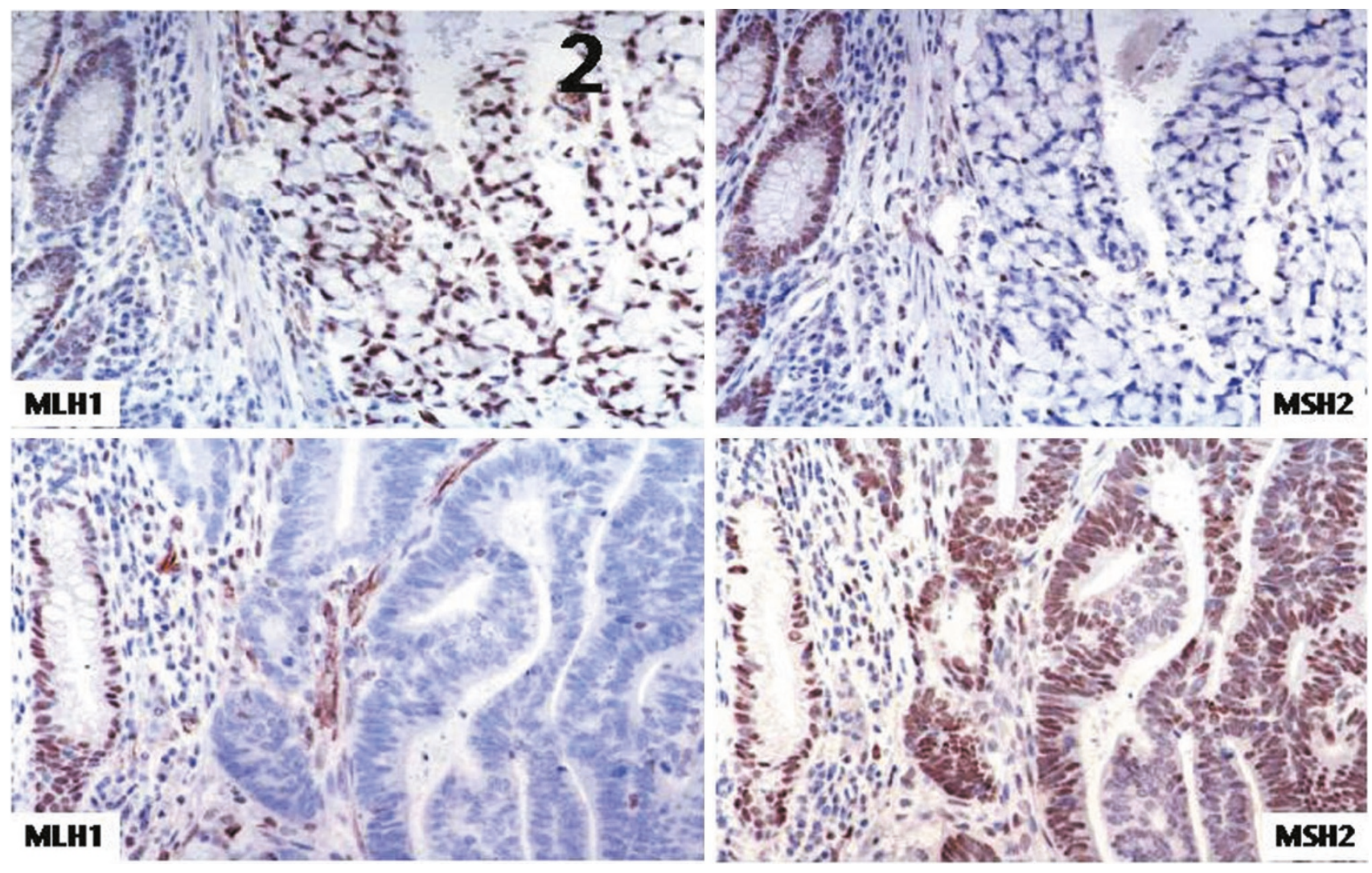

FIGURE 2. Mismatch Repair Gene Localization. Both MLH1 and MSH2 are normally expressed in crypt epithelial nuclei (to left of each field), which is utilized as an internal control for positive staining. The cancer in the upper panels has intact MLH1 staining (upper left) and absent MSH2 staining (upper right), whereas the cancer in the lower panels has absent MLH1 staining (lower left) and intact MSH2 staining (lower right). 
Hereditary Colorectal Cancer Testing Algorithms

Following the identification of the genetic basis of HNPCC, there has been a rapid expansion in management of hereditary colorectal cancer in the past 3 to 5 years $(19,26,27)$. The investigation of high-risk families is fairly uniform, and variations are due primarily to slight differences in methods available or favored by different labs. Most clinics have expanded high risk to include Amsterdam criteria as well as modifications that include extracolonic cancers. MSI testing is usually the first step. MSI-H cancers proceed to MLH1 and MSH2 immunohistochemistry, with subsequent germ line testing guided by these results. If immunohistochemistry is not available, germ line testing is initiated for both $M L H 1$ and MSH2. Patients whose colorectal cancers are MSI-L and MSS do not undergo further testing in most labs. Investigation of intermediate risk families is more variable, and more often funded by research protocols. In general MSI testing is still the first step, followed by immunohistochemistry. However, MLH1-deficient cancers are tested for methylation of the $M L H 1$ promoter region before germ line testing. The yield of germ line mismatch repair gene mutations in intermediate risk families is significantly lower than in highrisk families (less than $20 \%$ versus 50 to $75 \%$ positive, respectively). In addition, MSH6 testing is ongoing at some centers, and may be undertaken on MSI-H, MSI-L, and MSS colorectal cancers of either high or intermediate risk.

There are several different purposes for a genetic testing program. The motivating factor for most affected probands is to provide information to unaffected at-risk family members so that they may undergo predictive testing with appropriate subsequent screening and management depending on carrier status.

\section{Genomic Instability Pathways and Genetic Progression in Colorectal Cancer}

The identification of the microsatellite instability pathway indicates that there are at least two distinct pathways to colorectal cancer development (42; reviewed in Ref. 43). MSS cancers are typically aneuploid and characterized by widespread subchromosomal deletions (loss of heterozygosity), and, to a lesser extent, amplifications and translocations (often referred to as chromosomal instability). MSI-H cancers, on the other hand, are diploid, usually with no significant gross chromosomal changes, but with widespread subtle sequence alterations throughout the genome, particularly at sites of repetitive DNA. In addition, $A P C$ mutations, KRAS mutations, and p53 mutations are all more frequent in MSS cancers, whereas widespread methylation abnormalities and gene silencing are more common in MSI-H cancers (particularly sporadic tumors due to MLH1 methylation suppression) $(5,44-47)$.

In addition to differences in the frequency of alteration of targets known to be involved in colorectal cancer, MSI-H cancers also harbor mutations in a number of genetic targets that are relatively unique to this pathway. These target genes can be predicted from the observed hypermutability of mononucleotide tracts in yeast with DNA mismatch repair deficiency $(48,49)$. The inactivating mutations in MSI-H colorectal cancers cluster to similar hypermutable repetitive DNA sequences present in the coding regions of genes important to cell growth and cell survival, such as TGF $\beta R I I, I G F I I R$, E2F-4, BAX, Caspase-5 and MBD4 (50-55). All of these genes contain coding sequence mononucleotide tracts of 8 to 10 bases that are mutated in 30 to $80 \%$ of MSI-H colorectal cancers. In addition, whereas $A P C$ mutations may be less common, mutations in a downstream gene, beta-catenin, are significantly more common, supporting the importance of this pathway in colorectal neoplasia (17, 56).

\section{Biologic Significance of Genomic Instability Pathways}

There has been much promise in the past 10 years that advances in our molecular understanding of human cancer will translate into new approaches to diagnosis and management. Although there have been significant inroads into hereditary cancers, practical applications to sporadic neoplasia have not yet had major impact. In colorectal neoplasia, most research has focused on attempts to find associations between individual markers (such as aneuploidy, p53 mutations, KRAS mutations, Bcl-2 expression etc) and prognosis (reviewed in Ref. 3). To date, the molecular marker with the greatest possible predictive power has been loss of 18q genes (including DCC and others) (57). Although these latter markers are predictive of decreased survival, they have not moved into widespread clinical use.

Identification of the microsatellite instability pathway, on the other hand, has much greater potential as a likely molecular marker. Rather than being a measure of a single gene alteration, MSI identifies an entire pathway of genetic abnormalities. In fact, the pathogenesis of MSS and MSI-H colorectal cancers are so different, it may be reasonable to consider them as representing two different diseases. Interestingly, some of the previously studied molecular markers that have revealed promise as clinical predictors, may do so because they are surrogate markers of the MSS pathway. For instance, aneuploidy, 18q loss of heterozygosity, 


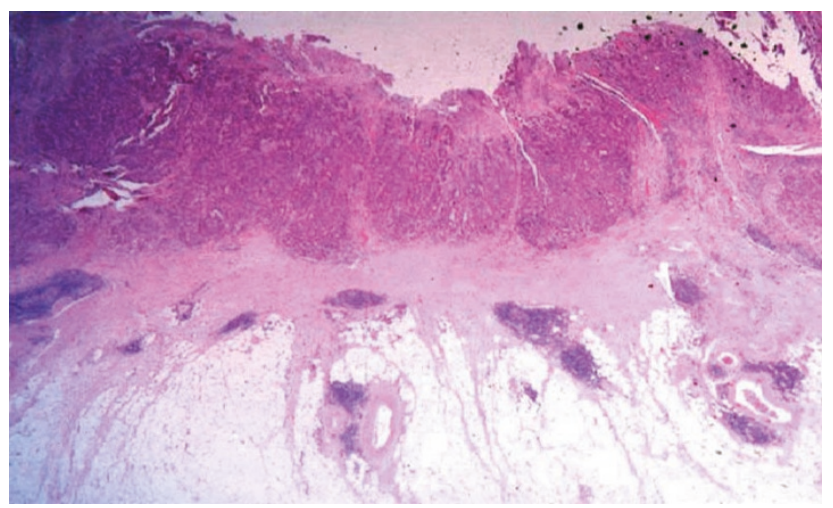

FIGURE 3. Colorectal Cancer with Microsatellite Instability. Low magnification of this MSI-H colon cancer reveals a pushing or expanding margin of invasion, poor differentiation, and a prominent Crohn's-like lymphoid reaction, characterized by peritumoral lymphoid aggregates, some with germinal centers.

and (to a lesser extent) p53 mutations are almost exclusively present in MSS tumors $(42,45,58)$.

\section{Pathologic Characteristics of Colorectal Cancers with Microsatellite Instability}

Some of the most definitive evidence of the likely biologic importance of the MSI pathway is present in studies clearly demonstrating the unique pathologic attributes of these cancers (see Refs. 59-61 for subsequent discussion). A number of earlier investigations of colorectal cancers from Amsterdam criteria HNPCC patients suggested significant differ- ences in clinical pathologic features and improved overall patient survival. The advent of MSI testing has allowed the definitive identification of a distinct subset of mismatch repair deficient tumors that can be readily analyzed. Although there are some suggestions of slight differences between sporadic and hereditary MSI-H cancers, most studies have considered these together. Although only colorectal cancers will be considered in this review, there are suggestions of unique associations with both endometrial and gastric cancers.

Overall, MSI-H cancers are more likely to be found in younger aged patients. Although this is most striking for HNPCC patients, there is also suggestion of a downward trend in age for sporadic MSI-H cancers. Patients with one MSI-H colorectal cancer are also more likely to have synchronous or metachronous cancers as well as extracolonic cancers (typically HNPCC-related). Grossly, MSI-H colorectal cancers are much more likely to be located in the right colon, and are typically bulky, polypoid or exophytic, and associated with abundant necrosis.

Microscopically, expanding rather than infiltrating margins of invasion are more common in MSI-H colorectal cancers (Fig. 3). MSI-H colorectal cancers are also more likely to be poorly differentiated and necrotic, and extracellular mucinous tumors, signet ring cell tumors, and undifferentiated and microglandular components are all over-
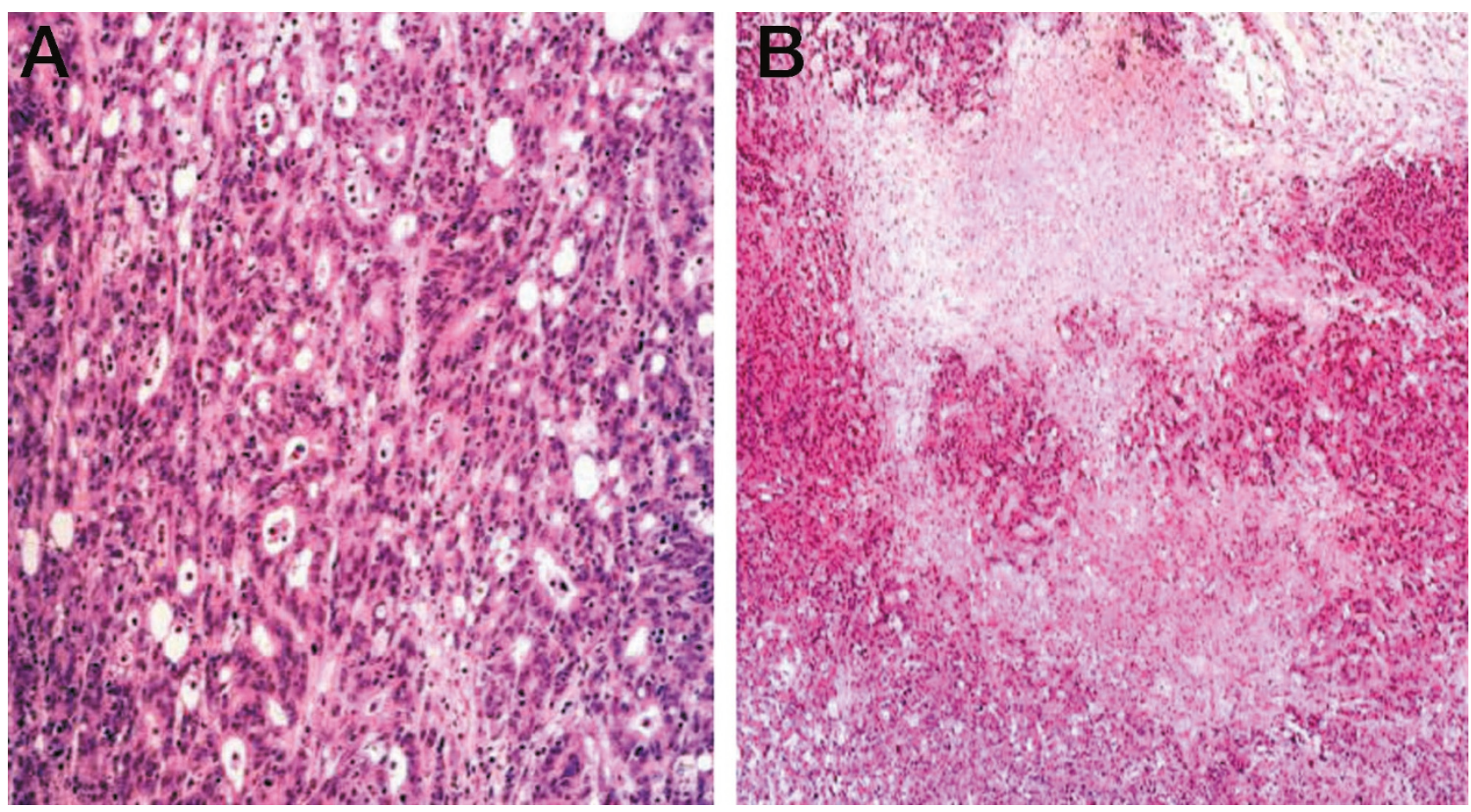

FIGURE 4. Microglandular Architecture and Necrosis in MSI-H Colorectal Cancer. Left, this MSI-H cancer has sheet-like morphology with multiple microlumina and anastomosing cords of cells, often referred to as a microglandular or cribriform morphology. Right, MSI-H cancer with extensive areas of geographic necrosis. 

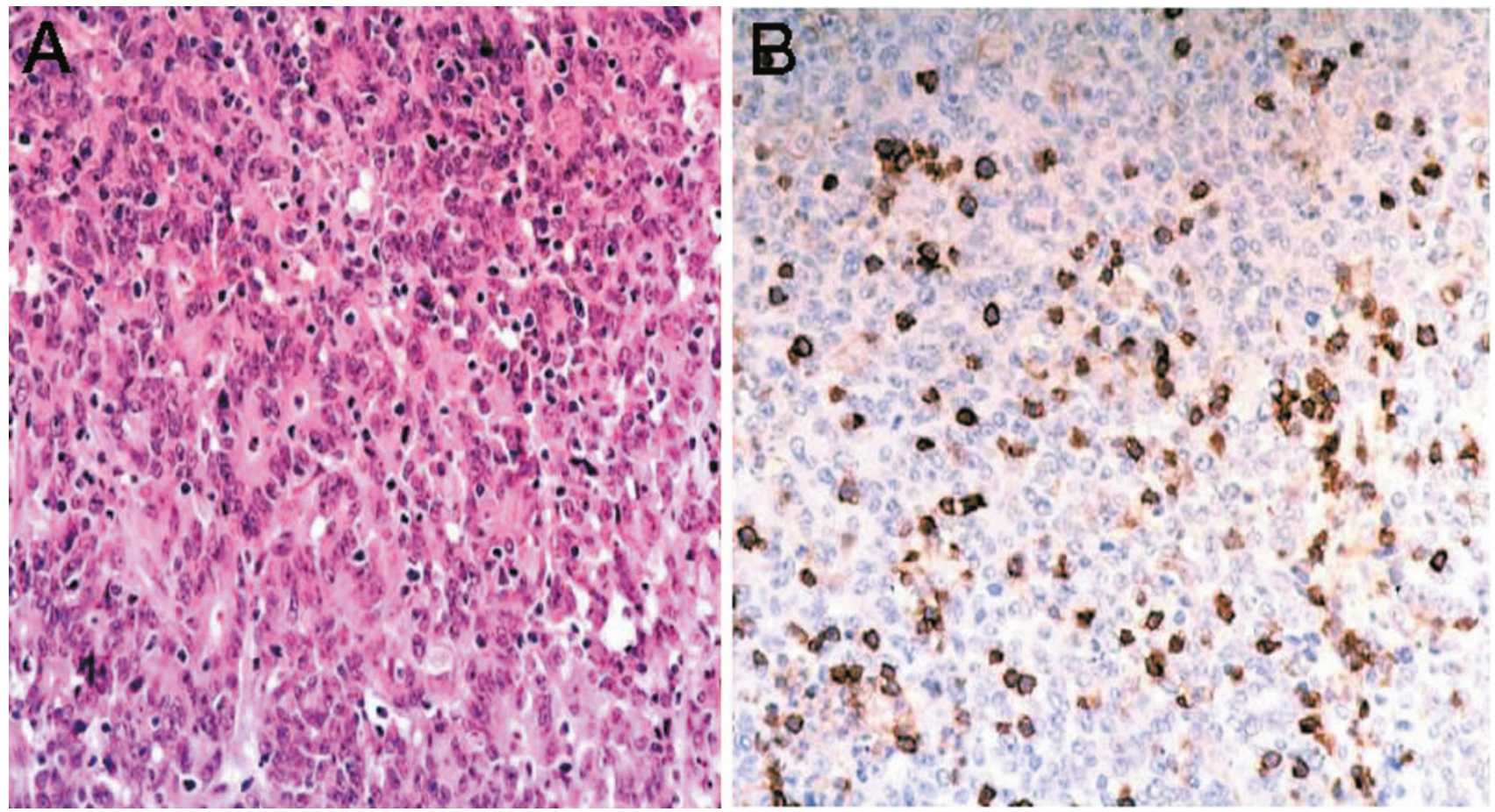

FIGURE 5. Tumor Infiltrating Lymphocytes in MSI-H Colorectal Cancer. Left, undifferentiated MSI-H colon cancer with a dense infiltrate of tumor-infiltrating lymphocytes. Right, same cancer stained with anti-CD3 antibodies highlights the infiltrating lymphocytes, and reveals that they are mostly T-cells.

represented (Fig. 4), although there is significant variability in the degree of these findings between different studies. Finally, a variety of different host immune responses, including peritumoral lymphocytes, peritumoral lymphocytes with lymphoid aggregates (Crohn's-like lymphoid reaction), and tumor infiltrating lymphocytes are all more frequent in colorectal cancers with MSI-H (Fig. 5).

Some attempts have been made to look at the sensitivity and specificity of various criteria in predicting MSI-H, as well as development of a hierarchical decision tree for classification. In general, although criteria have not yet been developed for definitive classification, right-sided location, undifferentiated or microglandular component (Fig. 7), and tumor infiltrating lymphocytes have the highest degrees of specificity (60).

\section{Clinical Behavior of Colorectal Cancers with Microsatellite Instability}

Beginning with older studies of colorectal cancers occurring in patients with HNPCC, there are now several investigations clearly demonstrating that MSI-H colorectal cancers are associated with an improvement in overall survival (61-63). In a recent multivariate analysis of more than 600 patients, MSI-H (in addition to AJCC Stage, histologic grade and extramural venous invasion) was found to be an independent predictor of outcome (hazard ratio $0.45, P<.001)$ (61). Furthermore, MSI-H cancers were significantly less likely to have metastasized for any given $\mathrm{T}$ stage (for instance 6/7 T4 N0 cancers were MSI-H), again highlighting the important differences in biologic behavior.

Several important questions remain. What is the response of MSI-H colorectal cancers to chemotherapy? In vitro studies suggest that MSI-H cell lines are more resistant to alkylating agents (64), although at least one clinical study suggests that MSI-H colon cancers are more chemosensitive (65). Is there a survival advantage associated with standard chemotherapy in MSI-H colorectal cancer? Can specific chemotherapies be developed to target and take advantage of DNA mismatch repair deficiency in tumor cells? What is the mechanism of the improved survival? Does the severity of the genomic instability render the cells more sensitive to apoptosis? Are invasion and metastasis genes less likely to be targeted? Does the prominent host immune reaction play a pathophysiologic role in the survival advantage? Answers to these and other questions in the coming years will likely yield additional important insights into this deadly disease.

\section{CONCLUSION}

The most significant recent advances in our understanding of colorectal neoplasia, and in possible new clinical applications, have arisen from the marriage of pathology, clinical oncology, genetics and 
basic science. In a back-and-forth exchange of ideas, observations by pathologists have been critical in delineating the stepwise genetic model of neoplastic progression and in identifying and characterizing genetic factors in cancer predisposition. Furthermore, application of the basic science advances back into clinical pathology and oncology provide the most compelling evidence that genetic factors can be used to define new disease subtypes. The pathologist sits in a unique position at the crossroads of these disciplines, and is a central player in the investigation, diagnosis, and management of hereditary cancers, as well as in the development of new tumor classification schemes. The rapid development of new technologies and the completion of the human genome project will provide pathologists with the opportunities to redefine their practice with unprecedented power compared with research developments over the past two centuries.

\section{REFERENCES}

1. Vogelstein B, Fearon ER, Hamilton SR, Kern SE, Preisinger AC, Leppert M, et al. Genetic alterations during colorectaltumor development. New Engl J Med 1988;319:525-32.

2. Fearon ER, Vogelstein B. A genetic model for colorectal tumorigenesis. Cell 1990;61:759-67.

3. Gryfe R, Swallow C, Bapat B, Redston M, Gallinger S, Couture J. Molecular biology of colorectal cancer. Curr Probl Cancer 1997;21:233-300.

4. Kinzler KW, Vogelstein B. Cancer-susceptibility genes. Gatekeepers and caretakers. Nature 1997;386:761.

5. Kinzler KW, Vogelstein B. Lessons from hereditary colorectal cancer. Cell 1996;87:159-70.

6. Groden J, Thliveris A, Samowitz W, Carlson M, Gelbert L, Albertsen $\mathrm{H}$, et al. Identification and characterization of the familial adenomatous polyposis coli gene. Cell 1991;66:589600.

7. Kinzler KW, Nilbert NC, Su LK, Vogelstein B, Bryan TM, Levy $\mathrm{DB}$, et al. Identification of FAP locus genes from chromosome 5q21. Science 1991;253:661-5.

8. Polakis P. The adenomatous polyposis coli (APC) tumor suppressor. Biochim Biophys Acta 1997;1332:F127-47.

9. Morin PJ. Beta-catenin signaling and cancer. Bioessays 1999; 21:1021-30.

10. He TC, Sparks AB, Rago C, Hermeking H, Zawel L, da Costa LT, et al. Identification of c-MYC as a target of the APC pathway. Science 1998;281:1509-12.

11. Tetsu O, McCormick F. Beta-catenin regulates expression of cyclin D1 in colon carcinoma cells. Nature 1999;398:422-6.

12. Fenoglio-Preiser CM, Noffsinger A. Aberrant crypt foci: a review. Toxicol Pathol 1999;27:632-42.

13. Bird RP. Role of aberrant crypt foci in understanding the pathogenesis of colon cancer. Cancer Lett 1995;93:55-71.

14. Jen J, Powell SM, Papadopoulos N, Smith KJ, Hamilton SR, Vogelstein B, et al. Molecular determinants of dysplasia in colorectal lesions. Cancer Res 1994;54:5523-6.

15. Su LK, Kinzler KW, Vogelstein B, Preisinger AC, Moser AR, Luongo C, et al. Multiple intestinal neoplasia caused by a mutation in the murine homolog of the APC gene. Science 1992;256:668-70.

16. Levy DB, Smith KJ, Beazer-Barclay Y, Hamilton SR, Vogelstein B, Kinzler KW. Inactivation of both APC. alleles in human and mouse tumors. Cancer Res 1994;54:5953-8.
17. Sparks AB, Morin PJ, Vogelstein B, Kinzler KW. Mutational analysis of the APC/beta-catenin/Tcf pathway in colorectal cancer. Cancer Res 1998;58:1130-4.

18. Lynch HT, Watson P. AFAP: variety is the spice of life. Gut 1998;43:451-2.

19. Petersen GM, Brensinger JD, Johnson KA, Giardiello FM. Genetic testing and counseling for hereditary forms of colorectal cancer. Cancer 1999;86:1720-30, 2540-50.

20. Laken SJ, Petersen GM, Gruber SB, Oddoux C, Ostrer H, Giardiello FM, et al. Familial colorectal cancer in Ashkenazim due to a hypermutable tract in APC. Nat Genet 1997;17: 79-83

21. Gryfe R, Di Nicola N, Gallinger S, Redston M. Somatic instability of the APC I1307K allele in colorectal neoplasia. Cancer Res 1998;58:4040-3.

22. Gryfe R, Di Nicola N, Lal G, Gallinger S, Redston M. Inherited colorectal polyposis and cancer risk of the APC I1307K polymorphism. Am J Hum Genet 1999;64:378-84.

23. Loeb LA. Mutator phenotype may be required for multistage carcinogenesis. Cancer Res 1991;51:3075-9.

24. Jackson AL, Loeb LA. The mutation rate and cancer. Genetics 1998;148:1483-90.

25. Cahill DP, Lengauer C, Yu J, Riggins GJ, Willson JK, Markowitz SD, et al. Mutations of mitotic checkpoint genes in human cancers. Nature 1998;392:300-3.

26. Lynch HT, de La Chapelle A. Genetic susceptibility to nonpolyposis colorectal cancer. J Med Genet 1999;36:801-18.

27. Lynch HT, Watson P, Shaw TG, Lynch JF, Harty AE, Franklin $\mathrm{BA}$, et al. Clinical impact of molecular genetic diagnosis, genetic counseling, and management of hereditary cancer: part II: hereditary nonpolyposis colorectal carcinoma as a model. Cancer 1999;86(S11):2457-63.

28. Bapat BV, Madlensky L, Temple LKF, Hiruki T, Redston M, Baron DL, et al. Family history characteristics, tumor microsatellite instability and germline MSH2 and MLH1 mutations in hereditary colorectal cancer. Hum Genet 1999;104: 167-76.

29. Ionov Y, Peinado MA, Malkhosyan S, Shibata D, Perucho M. Ubiquitous somatic mutations in simple repeated sequences reveal a new mechanism for colonic carcinogenesis. Nature 1993;363:558-61.

30. Aaltonen LA, Peltomaki P, Leach FS, Sistonen P, Pylkkanen L, Mecklin JP, et al. Clues to the pathogenesis of familial colorectal cancer. Science, 1993;260:812-6.

31. Thibodeau SN, Bren G, Schaid D. Microsatellite instability in cancer of the proximal colon. Science, 1993;260:816-9.

32. Jiricny J. Eukaryotic mismatch repair: an update. Mutation Res 1998;409:107-21.

33. Kolodner RD, Marsischky GT. Eukaryotic DNA mismatch repair. Curr Opin Genet Dev 1999;9:89-96.

34. Papadopoulos N, Lindblom A. Molecular basis of HNPCC: mutations of MMR genes. Hum Mutat 1997;10:89-99.

35. Herman JG, Umar A, Polyak K, Graff JR, Ahuja N, Issa JP, et al. Incidence and functional consequences of hMLH1 promoter hypermethylation in colorectal carcinoma. Proc Natl Acad Sci U S A 1998;95:6870-5.

36. Thibodeau SN, French AJ, Cunningham JM, Tester D, Burgart LJ, Roche PC, et al. Microsatellite instability in colorectal cancer: different mutator phenotypes and the principal involvement of hMLH1. Cancer Res 1998;58:1713-8.

37. Cunningham JM, Christensen ER, Tester DJ, Kim CY, Roche PC, Burgart LJ, et al. Hypermethylation of the hMLH1 promoter in colon cancer with microsatellite instability. Cancer Res 1998;58:3455-60.

38. Boland CR, Thibodeau SN, Hamilton SR, Sidransky D, Eshleman JR, Burt RW, et al. A National Cancer Institute Workshop on Microsatellite Instability for cancer detection and familial predisposition: development of international criteria 
for the determination of microsatellite instability in colorectal cancer. Cancer Res 1998;58:5248-57.

39. Marcus VA, Madlensky L, Gryfe R, Kim H, So K, Millar A, et al. Immunohistochemistry for hMLH1 and hMSH2: a practical test for DNA mismatch repair deficient tumors. Am J Surg Pathol 1999;23:1248-55.

40. Malkhosyan S, Rampino N, Yamamoto H, Perucho M. Frameshift mutator mutations. Nature 1996; 382(6591):499500.

41. Kolodner RD, Tytell JD, Schmeits JL, Kane MF, Gupta RD, Weger J, et al. Germ-line msh6 mutations in colorectal cancer families. Cancer Res 1999;59:5068-74.

42. Lengauer C, Kinzler KW, Vogelstein B. Genetic instability in colorectal cancers. Nature 1997;386(6625):623-7.

43. Lengauer C, Kinzler KW, Vogelstein B. Genetic instabilities in human cancer. Nature 1998;396:643.

44. Huang J, Papadopoulos N, McKinley AJ, Farrington SM, Curtis LJ, Wyllie AH, et al. APC mutations in colorectal tumors with mismatch repair deficiency. Proc Natl Acad Sci U S A 1996;93:9049-54.

45. Olschwang S, Hamelin R, Laurent-Puig P, Thuille B, De Rycke Y, Li YJ, et al. Alternative genetic pathways in colorectal carcinogenesis. Proc Natl Acad Sci U S A 1997;94:12122-7.

46. Fujiwara T, Stolker JM, Watanabe T, Rashid A, Longo P, Eshleman JR, et al. Accumulated clonal genetic alterations in familial and sporadic colorectal carcinomas with widespread instability in microsatellite sequences. Am J Pathol 1998;153: 1063-78.

47. Toyota M, Issa JP. CpG island methylator phenotypes in aging and cancer. Semin Cancer Biol 1999;9:349-57.

48. Tran HT, Keen JD, Kricker M, Resnick MA, Gordenin DA. Hypermutability of homonucleotide runs in mismatch repair and DNA polymerase proofreading yeast mutants. Mol Cell Biol 1997;17:2859-65.

49. Sia EA, Kokoska RJ, Dominska M, Greenwell P, Petes TD. Microsatellite instability in yeast: dependence on repeat unit size in DNA mismatch repair genes. Mol Cell Biol 1997;17: 2851-8.

50. Markowitz SD, Wang J, Myeroff L, Parsons R, Sun L, Lutterbaugh J, et al. Inactivation of the type II TGF-beta receptor in colon cancer cells with microsatellite instability. Science, 1995;268:1336-8.

51. Souza RE, Appel R, Yin J, Wang S, Smolinski KN, Abraham $\mathrm{JM}$, et al. Microsatellite instability in the insulin-like growth factor II receptor gene in gastrointestinal tumours. Nature Genet 1996;14:255-7.

52. Souza RF, Yin J, Smolinski KN, Zou TT, Wang S, Shi YQ, et al. Frequent mutation of the E2F-4 cell cycle gene in primary human gastrointestinal tumors. Cancer Res 1997; 57: $2350-3$.
53. Rampino N, Yamamoto H, Ionov Y, Li Y, Sawai H, Reed JC, et al. Somatic mutations in the BAX gene in colon cancers of the microsatellite mutator phenotype. Science 1997;275:967-9.

54. Schwartz S Jr, Yamamoto H, Navarro M, Maestro M, Reventos J, Perucho M. Frameshift mutations at mononucleotide repeats in caspase- 5 and other target genes in endometrial and gastrointestinal cancer of the microsatellite mutator phenotype. Cancer Res 1999;59:2995-3002.

55. Riccio A, Aaltonen LA, Godwin AK, Loukola A, Percesepe A, Salovaara $\mathrm{R}$, et al. The DNA repair gene MBD4 (MED1) is mutated in human carcinomas with microsatellite instability. Nature Genet 1999;23:266-8.

56. Mirabelli-Primadahl L, Gryfe R, Kim H, Millar A, Hsieh E, Christina, et al. Beta-catenin mutations are common in colorectal carcinomas with microsatellite instability but occur in endometrial carcinomas irrespective of mutator pathways. Cancer Res 1999;59:3346-51.

57. Jen J, Kim H, Piantadosi S, Liu ZF, Levitt RC, Sistonen P, et al. Allelic loss of chromosome 18q and prognosis in colorectal cancer. New Engl J Med 1994;331:213-21.

58. Cottu PH, Muzeau F, Estreicher A, Flejou JF, Iggo R, Thomas $\mathrm{G}$, et al. Inverse correlation between RER+ status and p53 mutation in colorectal cancer cell lines. Oncogene 1996;13: 2727-30.

59. Kim H, Jen J, Vogelstein B, Hamilton SR. Clinical and pathological characteristics of sporadic colorectal carcinomas with DNA replication errors in microsatellite sequences. Am J Pathol 1994;145:148-56.

60. Jass JR, Do KA, Simms LA, Iino H, Wynter C, Pillay SP, et al. Morphology of sporadic colorectal cancer with DNA replication errors. Gut 1998;42:673-9.

61. Gryfe R, Kim H, Hsieh ETK, Aronson MA, Holowaty EJ, Bull $\mathrm{SB}$, et al. Tumor microsatellite instability and patient survival in a population-based series of young colorectal cancer patients. New Engl J Med 2000;342:69-77.

62. Sankila R, Aaltonen LA, Jarvinen HJ, Mecklin JP. Better survival rates in patients with MLH1-associated hereditary colorectal cancer. Gastroenterology 1996;110:682-7.

63. Halling KC, French AJ, McDonnell SK, Burgart LJ, Schaid DJ, Peterson BJ, et al. Microsatellite instability and 8p allelic imbalance in stage B2 and C colorectal cancers. J Natl Cancer Inst 1999;91:1295-303.

64. Karran P, Hampson R. Genomic instability and tolerance to alkylating agents. Cancer Surv 1996;28:69-85.

65. Elsaleh H, Joseph D, Grieu F, Zeps N, Spry N, Iacopetta B. Association of tumour site and sex with survival benefit from adjuvant chemotherapy in colorectal cancer. Lancet 2000; 355:1745-50. 